\title{
Bland-Altman analysis for bias in estimates of scheduled versus actual times of operating room entry
}

\author{
Franklin Dexter, MD, PhD, FASA
}

Received: 29 February 2020/Revised: 2 March 2020/Published online: 14 April 2020

(c) Canadian Anesthesiologists' Society 2020

\section{To the Editor,}

Merchant compared scheduled vs actual times of operating room (OR) entry at British Columbia hospitals. ${ }^{1}$ His Table 2 shows the frequencies of different time differences (e.g., -1 to -30 min was $12.69 \%$ of the 7,770 cases at Royal Columbian Hospital). His conclusion was "that, in the Fraser Health Authority, the anesthesia start time for electively slated patients is within one hour of the slated time in $87 \%$ of cases, and cases start more than 90 min early in only $0.6 \%$ of cases."

Checklists for cohort studies include consideration of confounders because when confounding is present (as in virtually all observational studies), unadjusted percentages (i.e., the $87 \%$ and $0.6 \%$ ) are biased and thus unreliable for use for individual patients. Merchant refers to "case mix, patient population, and surgical predictability" as potential confounders. Nevertheless, the principal confounder is the scheduled start time itself. ${ }^{2}$ A case scheduled to enter the room at 8:00 AM is less likely to enter 90 min early than a case scheduled to enter the room at 4:00 $\mathrm{PM}^{2}$ (Readers interested in the mechanism of earliness and tardiness of case entry can refer to references ${ }^{2}$ and ${ }^{3}$ ).

To investigate this potential further, one could perform a Bland-Altman analysis, where the absolute values of Merchant's Table 2 differences are plotted on the vertical axis and the predicted (i.e., scheduled) OR times are plotted on the horizontal axis, with adjustment for workday

This letter is accompanied by a reply. Please see Can J Anesth 2020; 67: this issue.

F. Dexter, MD, PhD, FASA ( $\square)$

Department of Anesthesia, University of Iowa, Iowa City, IA,

USA

e-mail: Franklin-Dexter@UIowa.edu start times (e.g., start one-hour later than typical if meetings are held on Mondays). ${ }^{2-4}$

Among the 7,770 cases at Royal Columbian Hospital, and among the 123,865 cases at all Fraser Health Authority hospitals, what were the Spearman rank correlations between the absolute values of the time differences seen in Table 2 and the "slated time of room entry" in units of hours from each hospital's start of the workday? If either or both of these two Spearman correlations (one for the Royal Columbian Hospital and one for the entire data set) were substantive (e.g., $>0.3$ ), then Merchant's overall percentages would be sufficiently biased to influence decisions, compared with making different decisions by time of day and days of the week at each hospital. If applicable, and perhaps not as Merchant assumes because of hospitals' policies, then modification is simple to implement in practice so that each patient need not have unnecessary fasting. 2,3

Conflicts of interest None.

Disclosure The Division of Management Consulting of the University of Iowa's Department of Anesthesia provides consultations to corporations, hospitals, and individuals. This includes calculation of arrival times of patients. I receive no funds personally other than my salary and allowable expense reimbursements from the University of Iowa and have tenure with no incentive program. My family and I have no financial holdings in any company related to my work, other than indirectly through mutual funds for retirement. Income from the Division's consulting work is used to fund Division research.

Editorial responsibility This submission was handled by Dr. Philip M. Jones, Associate Editor, Canadian Journal of Anesthesia. 


\section{References}

1. Merchant RN. Slated versus actual operating room entry time in a British Columbia health authority. Can J Anesth 2020; DOI: https://doi.org/10.1007/s12630-020-01604-9.

2. Wachtel RE, Dexter F. A simple method for deciding when patients should be ready on the day of surgery without procedurespecific data. Anesth Analg 2007; 105: 127-40.
3. Wachtel RE, Dexter F. Influence of the operating room schedule on tardiness from scheduled start times. Anesth Analg 2009; 108: 1889-901.

4. Smallman B, Dexter F. Optimizing the arrival, waiting, and NPO times of children on the day of pediatric endoscopy procedures. Anesth Analg 2010; 110: 879-87.

Publisher's Note Springer Nature remains neutral with regard to jurisdictional claims in published maps and institutional affiliations. 